\title{
DESENVOLVIMENTO ECONÔMICO E CONDIÇÕES DE VIDA: A FORÇA DE UMA IDEIA E UMA IDEIA FORÇA NA OBRA DE ROBERTO SIMONSEN
}

\author{
ECONOMICAL DEVELOPMENT AND LIVING CONDITIONS: THE \\ STRENGTH OF AN IDEA AND A KEY IDEA IN THE WORK OF ROBERTO \\ SIMONSEN
}

\begin{abstract}
Moacir Freitas Junior ${ }^{1}$
\section{RESUMO}

O intento deste artigo é investigar a contribuição de Roberto Simonsen para o conhecimento e a melhora das condições de vida dos trabalhadores no Brasil. Nossa hipótese é a de que o intelectual contribuiu de maneira fundamental para que o tema das condições de vida dos trabalhadores, especialmente dos operários, fosse inserido em uma agenda mais ampla, a do nacional-desenvolvimentismo, para a qual também contribuiu de maneira significativa, conforme debateremos ao longo deste trabalho, sendo o tema o centro de suas teorias, o cerne, o alicerce do qual partiu para erguer o corolário de ideias sobre o Brasil e o mundo que o consagraram como um grande pensador no Brasil.
\end{abstract}

Palavras-chave: Industrialização. Condições de Vida. Nacional-desenvolvimentismo.

\begin{abstract}
The intent of this article is to investigate the contribution of Roberto Simonsen for the knowledge and the improvement of living conditions of workers in Brazil. Our hypothesis is that the intellectual contributed in a fundamental way to the theme of the living conditions of workers, especially workermen, was inserted into a broader agenda, that of "national-developmentalism", to which it also contributed significantly, as we will discuss throughout this work, being the subject at the center his theories, the core, the foundation of which he went to build the corollary of ideas about Brazil and the world that consecrated him as a great thinker in Brazil.
\end{abstract}

Keywords: Industrialization. Living Conditions. National developmentalism

\footnotetext{
${ }^{1}$ Doutor em Ciências Sociais pelo Programa de Pós Graduação da Faculdade de Ciências e Letras da UNESP de Araraquara. Coordenador Executivo da Secretaria Municipal de Governo de Araraquara. Email: moacirfreitasjr@yahoo.com.br
} 


\section{Introdução}

O presente artigo se propõe a estudar a importância que o tema da industrialização como forma de elevar as condições de vida teve para a construção intelectual e atuação política de Roberto Simonsen.

Simonsen foi um empresário e intelectual que se tornou um dos maiores líderes da burguesia industrial do Brasil da primeira metade do século XX. Foi, em grande parte, graças a suas ações que os industriais atuaram buscando influenciar a política econômica da época. Sua ascensão como pensador e líder de sua classe se deu ao mesmo tempo em que no Brasil ocorria, especialmente a partir da década de 1930, a implantação do capitalismo industrial, o fortalecimento do Estado como fator decisivo para a industrialização e, consequentemente, a chegada da burguesia nacional ao poder, para os quais contribuiu diretamente.

Em nosso entendimento, o tema do desenvolvimento como forma de superação da pobreza possui importância central para o autor, sua obra e sua atuação. É trabalhando esta questão que Simonsen depara, em 1919, com as precárias condições de vida dos operários da Companhia Construtora de Santos, o que o levou a construir um bairro popular, a Vila Belmiro; é a melhor qualidade de vida dos trabalhadores europeus e americanos, por ele testemunhada nas missões comerciais, que chamou a atenção do autor para o fato de que, nos países desenvolvidos, ainda que os operários não fossem ricos, eles mantinham um padrão de vida muitas vezes superior aos correlatos nacionais.

Da mesma forma, é a busca pela superação da pobreza que o levará aos históricos e importantíssimos debates com os liberais da década de 1940, oportunidade na qual o autor apresenta, de maneira pioneira, a tese do subdesenvolvimento, que se tornaria o marco dos estudos econômicos realizados no Brasil e em toda a América Latina a partir de 1949, com a publicação do Manifesto da Cepal.

É ainda por conta das condições de vida que Simonsen, como veremos mais detalhadamente, formula suas teses sobre a relação entre padrão de vida e industrialização, bem como toma contato com a sociologia, na qual via um método eficaz para determinar o ganho médio que um trabalhador precisaria ter para sua existência "digna", como dizia o autor.
Logo, a nossa hipótese é que o tema das condições de vida e de sua superação pelo desenvolvimento econômico industrial aparece em todas as fases do pensamento de Simonsen ao longo de sua carreira intelectual e prática, que caminham pari passo em sua trajetória de vida.

Neste trabalho, impossibilitados de abordar todo o percurso intelectual deste autor, concentraremos nossos estudos no momento histórico em que Simonsen apresenta a tese de que a industrialização era o único modelo capaz de superar o que entendia ser o principal problema nacional de então: o baixo padrão de vida, uma vez que o mesmo era fruto do modelo agroexportador adotado até então.

Esta formulação não aparece acabada na obra do autor tal como aqui a expusemos. Ela é fruto de anos de reflexão e carrega um grande valor simbólico, pois se até então a disputa entre industrialistas e cafeicultores se dava em campos mais teóricos, a partir da fundação da CIESP, em 1928, a mesma ganhou lances práticos.

E tal percepção, em nosso entender, é o nascimento de uma das ideias força do pensamento de Simonsen: sem aumentar o padrão de vida dos trabalhadores até o ponto em que eles possam subsistir e integrar o próprio mercado consumidor, o Brasil não se consolidaria como nação independente. Este, é claro, não era o único passo a ser dado em tal direção, mas era um deles, parte importante de um circuito de ideias que, na expectativa de Simonsen, elevariam o Brasil à condição de país desenvolvido.

Assim, escolhemos a fundação da CIESP, em 1928, para simbolizar o marco temporal no qual entendemos que o autor relaciona pela primeira vez as questões da industrialização brasileira com o crescimento econômico, o padrão de vida e a independência econômica do Brasil em relação aos demais países.

\section{Fundação da CIESP e a ideia de como superar a pobreza: com a industrialização}

$\mathrm{Na}$ obra Orientação Industrial Brasileira, de 1928, Simonsen associa pela primeira vez as condições de vida dos trabalhadores ao baixo padrão de produção e de consumo brasileiros, entendendo que somente a industrialização poderia transformar tal situação, elevando tais padrões e, 
consequentemente, a condição econômica nacional como um todo.

O autor afirma que a industrialização é considerada um padrão de medida de desenvolvimento de um povo. As pesquisas que são necessárias para o desenvolvimento de novas máquinas e produtos; os reduzidos preços dos produtos industrializados, com o consequente aumento da produtividade e outros fatores libertariam os homens do trabalho manual tal como era feito até então, embrutecedor, permitindo o aguçamento da inteligência dos trabalhadores e, como fruto do aumento de produtividade, o aumento de ganhos (SIMONSEN, 1932, p.168).

Acerca da carestia da vida, Simonsen avança sobre um importante tema: o do custo de vida da classe trabalhadora. O empresário e intelectual apresenta estatísticas dando conta de que o consumo per capita brasileiro nos anos 1920 era de trezentos réis anuais, ao passo que o da Argentina seria de um conto de réis (ou um milhão) e dos EUA cinco contos de réis (ou cinco milhões).

Partindo deste comparativo, a percepção de Simonsen era a de que os trabalhadores brasileiros ganhavam menos do que o necessário para custear sua subsistência, dando a falsa impressão de que a vida era cara, quando na verdade o que ocorria era o inverso: tão pouca era a remuneração do trabalho que se tornava impossível ao trabalhador sobreviver de maneira digna, sendo o resultado desta equação a perpetuação do atraso em que o país se encontrava, distante do grandes centros econômica e culturalmente.

$\mathrm{O}$ aumento deste ganho, ainda de acordo com o intelectual e empresário, só se daria pelo desenvolvimento da produção industrial, aumentando sua escala e qualidade, permitindo o acesso de mais indivíduos ao mercado consumidor, iniciando o círculo virtuoso do capital.

A percepção de Simonsen sobre a importância de o Brasil possuir um projeto de nação era ainda mais profunda, pois em seu entendimento o Brasil jamais seria um país plenamente independente sem rumar para a industrialização:

A independência política de uma nação só é efetiva em todos os seus aspectos se ela se baseia numa situação econômica forte, numa independência econômica relativa, sem a qual não existe de fato a independência política. Nas nações econômica e financeiramente fracas, o produtor nacional entrega os seus produtos, na permuta internacional, por valor inferior ao verdadeiro, em benefício de nações melhor organizadas. Não traduz, de fato, como que uma injusta restrição de sua liberdade, ser o produtor obrigado a entregar o fruto de seu trabalho em troca de valores inferiores? (SIMONSEN, 1932, p.177).

Em "As Crises do Brasil", artigo escrito por Simonsen em 1930, momento em que ocorria a Revolução de 30 no Brasil, há um aprofundamento em relação à necessidade de industrialização e de disputa com os interesses dos cafeicultores, tal como apontou Cepeda (2011). Isto porque, nesta etapa, a disputa entre os interesses agrários e industriais, entre outros fatores, por conta da crise de 1929, abre espaço para que os segundos busquem se afirmar enquanto classe.

Tal movimento que se iniciou, como vimos, em 1928, com a fundação da CIESP, e, posteriormente, da CNI, também elevou a argumentação de Simonsen e dos industriais: a carestia da vida era responsabilidade dos agroexportadores, uma vez que estes eram o sustentáculo da política de proteção do café, geradora de crises, e não dos industriais, cuja produção não tinha qualquer incentivo e ainda concorria com os produtos importados financiados pelos recursos obtidos com a venda da produção de café.

Cepeda (2011) entende que na primeira etapa de convivência entre industriais e agricultores, os segundos prevaleceram porque não havia, ainda, condições materiais, políticas e intelectuais capazes de inverter a questão sobre qual seria a prioridade economia brasileira.

Estabelecido em bases teóricas ricardianas, liberais, que apostavam na "mão invisível do mercado" e de sua autorregulamentação na divisão internacional do trabalho, as potências hegemônicas entendiam que caberia ao Brasil, assim como aos demais países periféricos, o papel de abastecedor do centro, caracterizado pelo modelo agroexportador no qual o centro pagaria com produtos manufaturados a importação de nossas matérias primas e produtos agrícolas, no caso o café. Então, essa seria a nossa vocação (CEPEDA, 2011).

Nesta passagem, os industriais defendiam, se não por convicção, por falta de opções, a manutenção deste modelo: 
O que caracteriza a primeira fase de aceitação da supremacia dos interesses primários é a condição incipiente da indústria nacional e sua fraca consciência política de se compreender como portadora de um interesse próprio, capaz de disputar a direção do Estado e a hegemonia política e social. Pesam aqui o diminuto tamanho das atividades industriais no conjunto da economia, mas também a dependência dos recursos originados na dinâmica poderosa da economia cafeeira. Neste momento, a cada lance de crescimento da economia mercantilexportadora, a distribuição de seus recursos via pagamento de trabalhadores ou da aquisição de produtos inter-capitalistas injetava dinâmica no restante da economia - em especial nos variados setores industriais, comerciais e urbanos. Não é a toa que durante mais de duas décadas a indústria e o comércio defenderam aguerridamente os mecanismos de proteção da economia do café (CEPEDA, 2011).

Os fatores que alteraram tal configuração social nasceram das próprias consequências da política cafeeira: o surgimento de um considerável mercado interno e, por conta disso, o aumento das atividades industriais, com a finalidade de suprir as novas demandas existentes tanto dos trabalhadores, agora assalariados e livres, quanto das demais classes sociais e até da própria atividade agrícola (CEPEDA, 2011).

A partir da crise mundial dos preços do café, a aliança tem suas bases materiais erodidas. Quando os preços do café caíram em escala mundial, a economia nacional foi diretamente afetada, colocando em risco parte considerável das elites exportadoras e também dos demais grupos sociais existentes, entre eles a indústria.

Por tal motivo, a resposta dada pelos cafeicultores de fazer com que o Estado adotasse políticas de proteção ao preço do produto foi apoiada pelos industriais, pois, naquele momento, a recuperação econômica era do interesse de todos:

A facilidade inicial do estabelecimento dessas políticas derivava do domínio das oligarquias exportadoras sobre o aparato estatal. Mas na verdade esta política também foi defendida por outros setores na medida em se difundia um nível de consciência da interdependência das várias atividades e da inédita condição sistêmica e nacional da economia. $\mathrm{Na}$ verdade este momento coloca como interesses coincidentes - não dependentes, mas também não divergentes - os dois setores sociais que digla- diavam já há algum tempo na tarefa de definir os rumos da economia nacional - o setor exportador versus o setor industrial (CEPEDA, 2011).

A autora explica que a disputa entre industriais e agroexportadores se desenrolou por pelo menos um século, sendo que as primeiras gerações de empresários industriais viam seus interesses representados pelos agricultores exportadores, que detinham a hegemonia política e econômica brasileiras, situação esta que somente se alteraria a partir da segunda geração de industrialistas: a de Roberto Simonsen, Evaldo Lodi, Jorge Street, Horácio Lafer e outros, os quais irão se conceber enquanto grupo detentor de interesses próprios, diferentes daqueles dos agroexportadores.

A partir destes movimentos não foi mais possível conciliar os interesses dos cafeicultores com os dos industriais, passando o confronto para uma nova etapa, mais estrutural e ideológica (CEPEDA, 2011).

Falando diretamente sobre o tema, Simonsen afirma que, seguindo pelo caminho de então (exportar café e importar manufaturados), em breve outra crise viria e inviabilizaria a economia brasileira, pois não mais nos seria possível pagar pelas trocas. E a consequência direta disso seria o maior empobrecimento da população.

Agricultores há que sonham, como remédio, oferecer em holocausto ao café todas as demais classes produtoras no Brasil que se transformaria, assim, num vasto cafezal. Supõem esses patrícios que, em troca do aumento da nossa importação, que na sua cifra atual já não podemos pagar, o mundo adquirirá o excesso de nosso café [...] fosse essa ideia exequível e teríamos apenas deslocado o problema no tempo, pois sem restrição da produção e com o afluxo de todos para a lavoura, haveria, em breve, outra superprodução e desta vez fatal, porque nada mais restaria ao Brasil para oferecer em troca de novos e hipotéticos mercados para o consumo da preciosa rubiácea. E o nosso padrão de vida já bastante baixo, desceria a níveis miseráveis (SIMONSEN, 1930, p.5).

Notemos que Simonsen retoma a ideia central desenvolvida em Orientação Industrial Brasileira, de que a causa da pobreza brasileira era o baixo ganho, fruto da também baixa - e ineficiente - produtividade, que só poderia ser superada pela racionalização da produção e da economia. 
Tratando especificamente das crises, suas causas e efeitos, Simonsen toma por norte a ideia de que a economia se organiza em torno da marcha do progresso e que esta segue em equilíbrio até que algum fator, que pode ser físico, político, moral, técnico ou social, entre outros, surja, desestabilizando a marcha e, com isso, gerando uma crise, efeito este que vinha se repetindo com maior frequência desde o século XIX, agravado, ademais, pelo fato de haver uma interdependência entre as nações, o que torna os momentos críticos "gerais", amplos, mundiais (SIMONSEN, 1930, p.9).

Especificamente sobre a crise daquele momento histórico (início da década de 1930), o empresário e intelectual afirma que as características que ela apresentava eram muito parecidas com as que motivaram os momentos críticos anteriores, a saber: periodicidade, superprodução e extensão mundial. Além disso, o autor percebe que as alterações advindas das crises econômicas alteram a realidade social de maneira marcante, consciência não muito bem definida naquele período da história intelectual brasileira:

Nos tempos de atividade econômica, os preços sobem; elevam-se lucros e salários; o número de desocupados diminui. No período de depressão diminui a atividade produtora, aumenta o número de desocupados, baixam os preços, produzindo, em sua queda, um recuo nos lucros e também nos salários. A crise é o momento da passagem da prosperidade à depressão, quando os preços iniciam a sua queda, quando os mercados parecem engorgitados de produção, quando os estoques aumentam perigosamente. (SIMONSEN, 1930, p.11).

Buscando entender a crise e seus reflexos mundiais e nacionais, Simonsen faz uma pequena digressão histórica, comparando acontecimentos similares já acontecidos, cruzando dados econômicos oriundos dos EUA, Inglaterra e Alemanha e citando estudos de diversos países para concluir que: 1) as crises são cíclicas; 2) os países em que a atividade econômica principal era agrícola saíram dos ciclos de crise mais enfraquecidos que os demais, pois foram vítimas da desproporção entre os preços e as matérias primas dos produtos manufaturados, noções estas que somente ficariam claras quase 20 anos depois, a primeira pela obra de Schumpeter (1939) e a segunda por Prebisch (1949).
Mais especificamente no Brasil, Simonsen aponta que, já no início do ano de 1929, os primeiros sinais da crise foram percebidos, com a diminuição do crédito internacional e dos afluxos de capitais e, por consequência, da diminuição das atividades comerciais do café, desequilibrando a balança comercial. O intelectual e empresário atribuía a crise a cinco fenômenos: superprodução do café; crise financeira internacional; política de redescontos do Banco do Brasil; agitação política; falta de elasticidade do meio circulante. Como agravante, todos estes fatores vigoravam em conjunto, de maneira interdependente.

Assim, Simonsen explica que a safra de café do período foi uma das maiores da história, aumentando a oferta do produto no mercado, em muito por conta das facilidades que a política de proteção conferia aos produtores. Na certeza de que não teriam prejuízos, uma vez que todo o café colhido era, grosso modo, comprado pelo Estado, o que importava era crescer a produção. E esta compra era financiada pelos recursos obtidos pela venda do produto no exterior e complementada por empréstimos externos. Ocorre que o mercado internacional já estava em crise, concentrando capitais na economia dos EUA e, consequentemente, retirando-os do Brasil:

Desde o ano passado esboça-se uma crise financeira internacional, agravada pela grande corrente especulativa, em torno dos títulos industriais, que se manifestou nos EUA. [...] Houve um verdadeiro afluxo de capitais estrangeiros para os Estados Unidos. O Federal Reserv Board procurou restringir as especulações, dificultando o crédito para este fim. Esta medida provocou a intensificação da evasão de capitais internacionais para os Estados Unidos, onde a taxa de juros para o call money, isto é, dinheiro pronto, garantido por títulos de primeira ordem, alcançou [...] 18\% ao ano!

[...] Ora, no Brasil, em plena fase do programa de estabilização monetária, anda sem moeda elástica, a nossa produção desenvolvia-se e intensificava-se baseada, principalmente, no crédito estrangeiro, que nos últimos anos não nos tem faltado. Com a atração do ouro para New York não só cessou o afluxo de capitais estrangeiros para o Brasil, como o crédito externo foi cerceado [...]. Só esta circunstância seria suficiente para gerar uma crise intensa (SIMONSEN, 1930, p.20). 
Ademais, a proibição do Banco do Brasil de descontar os títulos emitidos pelo Banco do Estado de São Paulo para financiar a lavoura impediu a sequência de estabilização de preços praticada pelo Instituto de Defesa do Café, praticamente inviabilizando a repetição do modelo, que segundo Simonsen foi "vítima, não causador" da crise econômica na qual o Brasil se viu inserido, pois após severo esforço para manter a política de valorização do então principal produto econômico nacional, o Instituto "viu-se [...] na impossibilidade de amparar a defesa do café nas bolsas, porque os saldos que possuía nesse estabelecimento bancário estavam todos empregados em auxílio direto à lavoura" (SIMONSEN, 1930, p.27).

Perante a negativa do governo de Washington Luiz de socorrer os produtores de café, que naquela oportunidade representavam os interesses de praticamente toda a burguesia, inclusive os dos industriais, dada a importância do café para a economia nacional, Simonsen aponta um rompimento político entre tais classes e o governo da época:

Mais uma vez as classes produtoras no Brasil eram vítimas da falta de continuidade e de espírito evolutivo, por parte dos poderes públicos, em matéria de política financeira. E no caso, viu-se o Governo Central agravando a crise e precipitando a sua evolução, concorrendo para a quebra do fator confiança nos institutos de crédito e de defesa da produção brasileira (SIMONSEN, 1930, p.29).

Em suma, entendemos que o autor defendia que a crise econômica pela qual o país passou naquele momento histórico era fruto das políticas de promoção e sustentação do café como único produto nacional, que teriam enfraquecido, tal como já ocorrera em outros países, a economia brasileira, incapaz de reagir à crise, bem como era uma barreira ao desenvolvimento de novas forças sociais, pois a política de exportação e importação até então praticada inviabilizava o fortalecimento da indústria nacional, bem como impedia a melhoria nas condições de vida da população. Diante de tal quadro, a industrialização seria a única forma de se "conseguir uma rápida melhoria no padrão de vida no Brasil" (SIMONSEN, 1930, p.43).

Para fundamentar sua hipótese de que o modelo agrário era o causador das seguidas crises econômicas pelas quais o Brasil passara ao longo dos anos 1920 até a derradeira, em 1929, o autor se propôs a estudar a história das crises econômicas acontecidas em outros países e as soluções por eles adotadas para o problema, concluindo, como vimos acima, que os países industrializados conseguiram superar as adversidades econômicas com maior rapidez e vigor que os demais, cujo modelo econômico era assentado na exportação de matérias primas.

Este era exatamente o caso do Brasil: com a economia escorada na exportação de café e sem qualquer incentivo ao desenvolvimento de outros produtos, o Brasil estava exposto a toda e qualquer crise internacional, sem poder de reação. Logo, tal como procederam os países centrais, a solução seria a industrialização, a única força capaz de desenvolver a economia brasileira e elevá-la aos moldes dos países centrais.

Neste sentido, em As Finanças e a Indústria, Simonsen reforça seus argumentos a favor da industrialização como forma de elevação do padrão de vida, chamando a atenção para o fato de que o Brasil estava atrasado em relação aos países centrais porque não possuía elementos de racionalização capazes de propor e executar soluções para os problemas nacionais.

$\mathrm{Na}$ passagem abaixo, o autor demonstra seus conhecimentos e seu inconformismo com a situação de pobreza a que estavam submetidos os trabalhadores, mais especificamente os do campo:

[...] somos um povo de fraca produtividade. Trabalhamos pouco e com pequena eficiência, sendo aqui mínimo o rendimento médio por cabeça. [...] não temos, praticamente, capitais próprios e nem economias. É impressionante a pobreza do nosso povo. Quem viaja pelo interior do país, quem visita a casa do caboclo, mesmo nos arredores de São Paulo, não deixa de ficar impressionado como um ser humano, no ano de 1931, se satisfaz com uma tapera de barro esburacada, coberta com sapé, tendo o chão de terra dura por piso e tarimbas, bancos toscos e esteiras por mobiliário. A alimentação do nosso homem de campo é rudimentar e insuficiente. Como se justifica que na época atual seja este o padrão de vida desse nosso homem com todas as conseqüências decorrentes desse atraso? (SIMONSEN, 1931, p.40).

O autor vai direto ao âmago do problema: o Brasil era um país pobre e que não produzia riquezas. O café, mesmo sendo o único produto aqui trabalha- 
do que possuía o que Simonsen chamava de "bem social", que entendemos ser um produto capaz de gerar riqueza, só servia para tanto até o limite de seu comércio internacional. As demais produções agrícolas que poderiam ser desenvolvidas não encontravam qualquer respaldo para tanto, nem financeiro, nem técnico, resultando em mais empobrecimento.

Logo, só restaria ao Brasil percorrer o mesmo caminho que os países centrais e socorrer-se da industrialização, a única força capaz de transformar em riqueza todas as potencialidades nacionais.

É numa política industrial fundada em bases racionais adequadas às condições de nosso meio que teremos que ir buscar, principalmente, a produção dos valores em bens sociais de que necessitamos para o rápido aumento de nosso poder aquisitivo e porque não dizê-lo, com os benéficos reflexos de adiantamento de processos de trabalho que a industrialização sempre conduz (SIMONSEN, 1931, p.41).

Mas a industrialização, tal como o café, só prosperaria se unisse em torno de si vertentes que os outros países desenvolveram, tais como o protecionismo, que feito em bases científicas seria essencial para a consolidação do novo modelo, bem como de um sistema bancário que financiasse as indústrias, de modo a permitir os investimentos e garantias necessárias à produção (SIMONSEN, 1931, p.40-45).

Simonsen argumenta, com o embasamento científico em estatísticas e fórmulas matemáticas, que o custo de vida nacional havia crescido na exata proporção da inflação, que por sua vez era causada pelo sistema de financiamento das exportações e importações. Em suma, a afirmação do autor era a de que a carestia da vida era fruto do modelo econômico agroexportador. Conclui o autor:

$1^{\circ}$ ) que o consumo dos produtos industriais no Brasil (aliás como em qualquer nação civilizada) é maior do que o dos produtos agrícolas; $2^{\circ}$ ) que as oscilações no custo de vida foram ocasionadas pelas inflações do meio circulante agravadas pelas variações no custo dos $25 \%$ de produtos industriais estrangeiros que consumimos; $3^{\circ}$ ) que a indústria brasileira, podendo desenvolver-se apoiada em aparelhamentos financeiros e bases técnicas convenientes, além de trazer o enriquecimento do país, melhoraria, incontestavelmente, as condições de estabilidade do custo de vida (SIMONSEN, 1931, p.50).
Logo, a industrialização seria o caminho para o progresso e para a superação da pobreza.

\section{Teoria e prática: a atuação de Simonsen como deputado e como líder de classe na defesa da industrialização como forma de elevar o pa- drão de vida}

No momento em que escreveu Ordem Econômica, Padrão de Vida e Algumas Realidades Brasileiras, de 1934, Roberto Simonsen se encontrava no posto de Deputado à Assembléia Constituinte representando o Estado de São Paulo.

Firme nos propósitos sobre os quais já discorremos anteriormente, Simonsen apresenta uma emenda ao anteprojeto da Constituição de 1934 com o objetivo de tornar a elevação e manutenção do padrão médio de vida um direito constitucional.

No discurso de apresentação da Emenda, não aprovada totalmente, porém exitosa ao obter o intento de inscrever naquela Carta o princípio econômico do padrão de vida, Simonsen discorre mais claramente sobre o que entende ser o "padrão mínimo", de espectro bem mais amplo do que o ganho financeiro propriamente dito.

O texto original da emenda apresentada pela bancada paulista, representada por Roberto Simonsen, era o seguinte:

Art. 113. A ordem econômica deve ser organizada conforme os princípios da justiça e as necessidades da vida nacional, visando o estabelecimento em todo o país de um padrão de vida compatível com a dignidade do homem. Dentro desses limites é garantida a liberdade econômica (SIMONSEN, 1934, p.9).

A inscrição do tema "padrão de vida" como princípio constitucional, para além de um movimento dotado de grande simbolismo se tratando da consolidação de direitos, também sinalizava a adoção, por Simonsen, daquele conceito como balizador de suas ações e pensamentos.

Nossa afirmação decorre do fato de que, das várias formas como a questão poderia ser abordada, ou mesmo não ser, considerando a situação brasileira na época, Simonsen fez questão de instruir o debate sobre o tema com o claro intuito de torná-lo um ponto de destaque da agenda constitucional, portanto um 
direito o qual os governantes não poderiam, em tese, ignorar.

Vemos, assim, que na proposta, o conceito de "padrão de vida" se tornou o centro da ordem econômica, pois, acompanhando a redação, a "liberdade econômica" estaria contida "dentro de limites", que no caso eram os "princípios da justiça e as necessidades da vida nacional, visando o estabelecimento em todo o país de um padrão de vida compatível com a dignidade do homem".

Em outras palavras, a liberdade econômica estaria condicionada à elevação e manutenção de um padrão de vida digno, situação bem diferente da conhecida - e combatida - pelo autor.

Entendemos ser esta uma passagem crucial para a compreensão do pensamento e da estratégia de Simonsen: se antes a questão das condições de vida aparecia enquanto pensamentos e discursos, ainda que não menos importantes, nesta oportunidade o autor trava um debate direto sobre o tema com as demais lideranças políticas de então, desejando tornar sua ideia de progresso econômico um princípio para o Estado brasileiro.

O próprio autor, na obra Níveis de Vida e a Economia Nacional, de 1940, seis anos após sua passagem pelo Congresso Nacional, declarou que sua intenção com a inserção do conceito de padrão de vida na Constituição de 1934 era, de fato, fomentar o debate sobre o tema:

Pela primeira vez, na carta constitucional de um país, em 1934, por sugestão minha, representante que era das classes patronais de São Paulo, se fez incluir a obrigação do levantamento periódico, por parte dos poderes públicos, dos níveis de vida nas várias regiões do país. Justificando tal iniciativa, acentuei a necessidade de terem os governantes constantemente sob seus olhos a carta das condições de vida das populações, afim de que constituísse sua constante preocupação, o emprego de todos os meios adequados e possíveis à sua melhoria (SIMONSEN, 1940, p.15).

Assim, temos uma passagem à ação de Simonsen com relação aos temas que o mobilizaram pelos próximos quinze anos, período em que promoveu o debate sobre a industrialização do Brasil.

Outro aspecto que se depreende do artigo em análise é o debate com a linha de pensamento econômico liberal, que se delineará com mais clareza nos anos seguintes de atividade do autor. Antagônica aos preceitos liberais, a proposta de Simonsen era em tudo consistente com a linha de pensamento que paulatinamente construiu desde a década de 1910: a economia deveria se guiar não pela liberdade plena dos mercados, mas pela racionalização de suas vertentes, bem como caberia ao Estado papel mais relevante no campo econômico:

O caráter de exagerada restrição da capacidade do Estado, que se poderia, talvez injustamente, imputar à Constituição de 1891, está modificado pela adoção de medidas de alto alcance social e político. Foi aumentada a esfera de ação do Estado no campo econômico; a complexidade dos modernos problemas econômicos e sociais e a presença de grupos foi reconhecida pela aceitação dos conselhos técnicos e foi incluída, como um dos propósitos essenciais de governo, a melhoria do padrão de vida do brasileiro (SIMONSEN, 1934, p.9).

$\mathrm{O}$ autor reforça este pensamento com outras passagens, nas quais, basicamente, propõe diretamente a intervenção do Estado na economia como forma de limitar os conflitos sociais, uma vez que poderia racionalizar e harmonizar os elementos de mercado:

O Estado [...], num país como o nosso, pode estimular e amparar a produção, proteger o trabalho, determinar rumos coordenadores e sãos para que esses fatores se processem num ambiente de harmonia, reduzindo ao mínimo os atritos criadores dos problemas sociais (SIMONSEN, 1934, p.12).

Ainda sobre o papel do Estado, o autor segue esgrimindo com os princípios liberais e aproveita para delinear com maior clareza sua ideia de racionalização da economia por intermédio do Estado, que deveria intervir com o fito de organizar a vida econômica, algo inalcançável pela via do mercado:

De fato, não existe país algum no mundo em que se tenha observado integralmente os postulados puríssimos da escola liberal, pois que a observação direta dos fenômenos e das atividades sociais demonstra que mais de três quartas partes de nossos atos tem origem no campo econômico, e, portanto, o "laisser faire" e o "laisser passer", absolutos por parte do Estado, seriam sempre uma utopia (SIMONSEN, 1934, p.13). 
Tratando-se especificamente da pobreza nacional, que em sua explanação justificaria a adoção da emenda, Simonsen caminha por aspectos que em seu ver são parte do conjunto de causas da carestia nacional: ausência de uma moeda de valor estável; ausência de um sistema financeiro próprio; completo desconhecimento da situação física (geográfica, cremos) que facilita a subsistência, mas impede a reprodução das riquezas; por fim, a ausência de mecanismos de observação dos fenômenos sociais. Todos estes fatores, somados, impediriam o Brasil de elevar o padrão de vida de seu povo.

Constitui, por certo, uma angustiosa interrogação para todos os brasileiros que estudam os problemas nacionais, a razão de não poder o nosso homem médio adotar um padrão de vida equivalente aos que apresentam os países mais adiantados. E surge a evidência de nossa pobreza, corroborada pela insuficiência de nossas rendas públicas e por infalíveis índices que a técnica financeira vai apontando (SIMONSEN, 1934, p.16).

Citando um estudo de instituto alemão de estatísticas que classificou o Brasil como "neo-capitalista", cuja produção de capital era insuficiente para sua própria subsistência, Simonsen aprofunda sua tese sobre a relação pobreza-subdesenvolvimento que anos depois será o mote de sua atuação: éramos "um país pobre, habitado por uma população pobre" e, diante de tal quadro,

[...] as declarações dos direitos sociais brasileiros devem ser, portanto, orientadas no sentido de estimular toda e qualquer iniciativa digna, que traga um progresso real ao país, [...] e emulação de todos os fatores que determinem uma melhoria no padrão de vida do brasileiro (SIMONSEN, 1934, p.18).

Temos agora mais bem delineado um dos pressupostos da chave interpretativa de Simonsen: o Brasil era pobre porque produzia menos do que necessitava e era habitado por uma população pobre, que vivia basicamente em regime de subsistência, incapaz, portanto, de gerar novas riquezas, e o sistema agrário era o responsável por esse estado.

Assim sendo, o centro das ações econômicas deveria ser elevar os níveis de produção e, consequentemente, de ganhos da classe trabalhadora, resultando de tais ações a elevação do padrão de vida desta classe, o que por sua vez faria girar o círculo virtuoso do capitalismo impulsionado pela indústria, tal como acontecera nos EUA, na Alemanha, na Inglaterra e em outros países que o autor tomou por exemplos.

Faltava neste ciclo argumentativo o outro pressuposto do pensamento de Simonsen, a industrialização, que completa a linha aqui perseguida: condições de vida - industrialização - progresso.

Mas qual seria, então, o "padrão" que o Brasil deveria perseguir? $\mathrm{O}$ autor entende que:

Por padrão de vida digno, eu definiria a situação de recursos e de cultura que consegue o indivíduo para que se sinta capaz de constituir família, garantindo a sua subsistência, e se orientando convenientemente em harmonia com o progresso social (SIMONSEN, 1934, p.18).

Como se verifica, tanto o conceito de pobreza como o de riqueza, para Simonsen, tinham significado amplo: a pobreza a ser vencida era a material, a cultural e a social; da mesma forma, a riqueza almejada não era só a dos altos salários, mas sim de todo este conjunto de elementos que transformaria a sociedade atrasada da época em outra, preparada para o ingresso no mundo moderno do capitalismo industrial.

Ressaltamos: vencer a "pobreza" era, para Simonsen, o pressuposto para o ingresso do Brasil no estreito patamar de nação rica, central, em contraponto com a situação periférica da época, trilhando um caminho que reproduzia o percurso e levava ao destino que os países desenvolvidos da época fizeram. A ideia força, aqui, está clara: naquelas nações, foi o incremento da industrialização que possibilitou tal progresso social. Não haveria, portanto, de ser diferente no Brasil.

Assim, o conceito de padrão de vida como ponto de apoio intelectual para o debate sobre a superação da pobreza serviu, em nossa visão, de plataforma para os debates sobre a industrialização, nos quais a carestia era tema recorrente e sobre o qual Simonsen pode, com maior propriedade, discorrer em torno da definição que agora antecipamos: para vencer a pobreza era necessária a industrialização, pois a economia agroexportadora não só era a causadora de tal situação como não tinha mais energias para superá-la, por conta, inclusive, do próprio atraso tecnológico e econômico em que se encontrava. 
Notemos agora como a linha argumentativa de Simonsen está completa e apta para o travamento dos debates futuros: o Brasil é um país pobre, habitado por um povo pobre, e esta pobreza é decorrente da baixa efetividade de nossa produção, bem como do pouco valor social do que é produzido, no caso, do café, que, como o próprio autor demonstrou, só se valoriza até o limite de sua demanda. Todo o excesso produzido não gera riqueza, pois não é exportado e nem consumido internamente. Soma-se a isso a comprovação, também já feita pelo autor, de que o café vinha se desvalorizando continuamente em relação aos produtos manufaturados, depreciando seu preço, e consequentemente, os ganhos dele advindos.

Logo, pela via do modelo agroexportador não seria mais possível para o Brasil alcançar o status de nação rica, pois seria preciso alterar o modelo produtivo agrário para outro, capaz de gerar mais riquezas e ativar o ciclo do capitalismo: o industrial.

Nas próximas passagens do autor que iremos analisar ao longo deste trabalho, a relação causal indústria - condição de vida - progresso será constantemente reafirmada, como argumentação de ordem científica, tal como preferia o autor, mas com função também ideológica: defender os interesses dos industriais brasileiros.

Uma destas oportunidades aparece em "Níveis de Vida e a Economia Nacional", conferência para um centro administrado pela igreja católica, em que o autor expõe suas teses sobre padrão de vida e industrialização, tal como já havia feito anteriormente.

Abordando diretamente os temas em análise nesta seção, Simonsen retoma seu conceito de padrão de vida, classificando-o como de mínimo conforto e associando-o a outro parâmetro, o de civilização. Portanto, seriam mais civilizados os povos em que o padrão de vida fosse mais elevado. E o que determinaria esta elevação ou não do padrão de vida seriam a produtividade, a produção e a riqueza dela proveniente (SIMONSEN, 1940, p.10).

Discorrendo sobre o caso brasileiro e as diferenças de desenvolvimento humano existentes no próprio território nacional, que no comparativo apresentado pelo autor eram as regiões Norte e Sudeste do Brasil, o primeiro mais agrário e o segundo mais industrializado, Simonsen reafirma sua tese: no Sudeste, não só o padrão de vida era melhor como também os fatores culturais e sociais eram mais desenvolvidos. Da mesma forma, os valores dos bens produzidos eram maiores que os dos extraídos da região Norte (SIMONSEN, 1940, p.13).

Quanto às causas da carestia nacional, o autor repete de maneira mais refinada sua abordagem sobre o tema, explicando que, ao contrário do que ocorre nos países ricos, nosso problema não é de má distribuição, mas de falta do que ser distribuído.

Verifica-se, porém, que a origem da existência desses baixos níveis é bem diversa do que constata em alguns grandes países de densa população, de fartos recursos econômicos e de grande progresso material. Ali, muitas vezes, existe a miséria imerecida, proveniente da má distribuição dos proventos do trabalho; aqui, apura-se que, em larga escala, $a$ pobreza decorre da insuficiência da produção, do atraso e da instabilidade do meio. [...] Todos reconhecem esta insuficiência e os que examinarem, com sinceridade, os assuntos nacionais, hão de verificar que ela não decorre aqui de um problema de distribuição, mas senão, ou principalmente, do problema da criação e da produção (SIMONSEN, 1940, p.14, grifos nossos).

E para superar a pobreza a solução era o aumento da produção, que

[...] só em pequena escala pode ser obtida por imposições de uma avançada legislação social. A alta geral dos níveis de vida depende de fortes iniciativas de ordem econômica, que não devem nem podem mais ser proteladas, sob pena de vermos agravadas continuamente as disparidades flagrantes que já nos ferem (SIMONSEN, 1940, p.15).

Mas estas ações fortes no campo da economia, por certo, não poderiam se dar pela via do mercado, mas sim pela do Estado, único ente capaz de, naquele momento histórico, reunir e organizar as forças produtivas existentes (SIMONSEN, 1940, p.16).

$\mathrm{O}$ que o autor desejava com esta passagem, a nosso ver, era concluir, embora não o tenha feito de maneira direta, que o Estado deveria auxiliar na implantação da indústria, adotando políticas de proteção tal como fazia com a agricultura do café; a legitimidade se daria tal como ocorreu com a lavoura: sendo o centro da economia nacional, era correto que o Estado atuasse em sua proteção. Se tal papel cabe agora à indústria, a mesma proteção the deve ser dada. 
Cepeda (2011) desenvolve com acuidade esta ideia. De acordo com a autora, a lógica da proteção às atividades cafeeiras se legitimava no primado de que era justo o esforço nacional pela proteção do café porque era através dele que a economia se sustentava. A exportação do café seria nossa vocação e, portanto, nosso progresso.

A crise, que não pôde ser superada pelos mecanismos até então existentes, desfigurou o raciocínio agroexportador concretamente, sendo que nem as proteções estatais puderam fazer voltar o progresso, e o custo social de sua manutenção era latente.

Diante deste quadro, coube aos industriais se apropriar desta mesma lógica, mas em seu favor: se a economia precisa de um esteio e o café não consegue mais desempenhar tal função, seria o caso de apostarmos em outras atividades econômicas, no caso, a indústria. Notemos que a matriz é a mesma: o Estado atuando na economia para defender os interesses nacionais. Vera Cepeda sintetiza essa linha de raciocínio e argumentação, que assemelha os interesses economicamente dominantes - ora do café, ora da indústria - aos do conjunto da nação da seguinte forma:

O setor industrial aproveita-se dessa brecha aberta: se o progresso nacional, se a nação precisa de um suporte econômico forte, e se o café não demonstra essa capacidade, então não devemos apostar em outra atividade, capaz de auto-sustentação - como a indústria? E se sim, como a divisão internacional do comércio aparecia como responsável pela assimetria econômica na periferia, dificultando não só a atividade agrícola, mas principalmente impedindo o surgimento de outras mais resistentes e promissoras como a atividade industrial, então seria preciso a) afastar-se da interpretação do liberalismo clássico (e recusar suas premissas, b) usar a energia social condensada no Estado na proteção da atividade industrial. Ergo: a ação dirigida do Estado no campo econômico apoiando-se na defesa da nação estava construída (CEPEDA, 2011).

\section{Conclusão: industrialização para superação da pobreza}

Em suma, a industrialização ganhou corpo a partir, entre outras, das ações intelectuais e práticas de Simonsen, que deram à ideia o arcabouço científico e o acabamento ideológico necessários para que o tema assumisse a condição de projeto nacional, tendo por base, a nosso ver, a questão da carestia, da pobreza e dos padrões de vida e das formas de sua elevação, temas que entendemos constituir o cerne do pensamento de Roberto Simonsen.

Como já foi dito anteriormente, nossa intenção era demonstrar como o problema das condições de vida teve para Simonsen importância fundamental, balizando sua atuação enquanto líder de sua classe, deputado, empresário, enfim, nas várias faces de sua atuação. Buscamos percorrer parte da caminhada intelectual do empresário dentro do período histórico assinalado, descrita, nas diversas obras aqui debatidas, quanto a sua atuação prática - dimensões que, neste caso, se confundem a todo o momento, conformando assim um traço da personalidade do autor -, em que o mesmo caminha da formulação inicial de sua chave interpretativa, ainda no tempo da intervenção em Santos, até o momento em que parte para a ação prática, defendendo suas ideias como deputado, na sociedade civil organizada da época.

A preocupação de Simonsen com a pobreza é o elo entre as ideias e lutas travadas pelo intelectual e empresário para desenvolver o Brasil ao longo de sua vida. A nosso ver, fazem parte da chave de raciocínio que Simonsen aprofundou ao longo de sua trajetória: pobreza - baixos rendimentos - produtos coloniais; industrialização - riqueza - melhoria nas condições de vida - trocas internacionais mais justas - maior desenvolvimento.

A industrialização, então, não seria um fim em si mesmo, mas o meio pelo qual o Brasil poderia aumentar sua renda per capita e, com isso, mudar de patamar econômico, tal como fizeram os países centrais.

Dada a complexidade da obra do autor, não se pode afirmar que somente esta questão foi a base de todo seu pensamento, mas nosso entendimento é que a superação da pobreza - que depois resultou, como bem destacou Cepeda (2007 e 2011) na tese do subdesenvolvimento, de importância científica ímpar -é sem dúvida um dos, se não o principal, pilares de sua atuação intelectual, e que, não obstante as divergências existentes, resultou em contribuição concreta para o pensamento social brasileiro. 


\section{Referências bibliográficas}

BERLINK, CYRO. Roberto Simonsen: a indústria, as ciências sociais e a realidade brasileira. São Paulo: Escola Livre de Sociologia e Política de São Paulo, 1948.

. Comemorações do $\mathbf{4 0}^{\circ}$ aniversário da Escola de Sociologia e Política de São Paulo. Ciências Políticas e Sociais, São Paulo, v.2, nº 3, setembro de 1964.

. Liderança e liberdade. Revista Sociologia - Revista dedicada à teoria e à pesquisa nas ciências sociais. São Paulo: Sociologia e Política, vol. 26, setembro de 1964, p. 281-305

BIELSCHOWSKY, Ricardo. Pensamento Econômico Brasileiro. $O$ ciclo ideológico do desenvolvimentismo. $4^{\mathrm{a}}$ edição, Rio de Janeiro: Contraponto, 2000.

CARDOSO, Fernando Henrique. Empresariado industrial e desenvolvimento econômico no Brasil. São Paulo: Difel, 1972.

CARONE, Edgard. Roberto C. Simonsen e sua Obra. RAE - Revista de Administração de Empresas, Rio de Janeiro: 11(4): p.23-28, out/dez de 1971.

CARONE, Edgard. O pensamento industrial no Brasil. 1880-1945. Rio de Janeiro/São Paulo: Difel, 1977.

CASTRO, Josué. As Condições de vida das classes operárias do Recife. Revista do Arquivo Municipal, São Paulo, vol. 18, 1935, pp.167-178.

CEPEDA, Vera. Roberto Simonsen e a formação da ideologia industrial no Brasil: limites e impasses. 2004. Tese. (Doutorado em Ciência Política) - Faculdade de Filosofia, Letras e Ciências Humanas, Universidade de São Paulo, São Paulo.

Estado, Democracia e Nação na teoria do subdesenvolvimento. Trabalho apresentado no XII Encontro Nacional de Economia Política, junho de 2007. Disponível em: <http://www.sep.org.br/artigo/861 d4b012a6ed845f6bac443e6cd55e34a7.pdf>. Último acesso em 30 de set. de 2009.

O problema do moderno no pensamento de Roberto Simonsen: crítica ao liberalismo e a questão nacional. In: XV Congresso Brasileiro de Sociologia, 2011, Curitiba. Anais do XV Congresso Brasileiro de Sociologia, 2011, sem paginação.

COLISTETE, Renato Perim. A força das idéias: a CEPAL e os industriais paulistas na primeira metade da década de 1950. In História Econômica \& História de Empresas, vol. X , 2006, p. 123-153.

FURTADO, Celso. Formação Econômica do Brasil. Companhia Editora Nacional, São Paulo, 1998.

IANNI, Octávio. Estado e Capitalismo. $2^{\mathrm{a}}$ ed. Editora Brasiliense: São Paulo, 1989.
LEME, Marisa Saenz. A Ideologia dos Industriais Brasileiros (1919-1945). Petrópolis: Vozes, 1978.

LIMA, Heitor Ferreira. Mauá e Roberto Simonsen: dois pioneiros do desenvolvimento. São Paulo: Edaglit, 1963.

Três industrialistas brasileiros: Mauá, Rui Barbosa, Roberto Simonsen. São Paulo: Alfa-Ômega, 1976.

PREBISCH, Raul. O Desenvolvimento Econômico da América Latina e seus principais problemas. Revista Brasileira de Economia, Vol. 3, nº 3, 1949.

SCHUMPETER, J. Business Cycles: A Theoretical, Historical and Statistical Analysis of the Capitalist Process. New York, London: McGraw-Hill, 1939

SIMONSEN, Roberto. Orientação industrial brasileira. São Paulo: São Paulo Editora Ltda, 1928.

As crises no Brasil. São Paulo: São Paulo Editora, 1930.

- A construção dos quartéis para o Exército. São Paulo: sem editora, 1931a.

- As finanças e a indústria. São Paulo: São Paulo Editora, 1931 b.

. À margem da Profissão - discursos, conferências e publicações. São Paulo: São Paulo Editora, 1932.

. Rumo à verdade. São Paulo: São Paulo Editora, 1933.

- Ordem econômica, padrão de vida e algumas realidades brasileiras. São Paulo: São Paulo Editora, 1934.

- A evolução industrial do Brasil. São Paulo: Empresa Gráfica da Revista dos Tribunais, 1939.

- Níveis de vida e a economia nacional. São Paulo, sem editora, 1940.
Recebido em 30 de maio de 2013

Aceito em 08 de outubro de 2013 